\title{
STUDI KASUS PERILAKU MENYIMPANG SISWA DI SD NEGERI GAYAMSARI 01
}

\author{
Noor Kholifah Sa'idah ${ }^{1}$, Khusnul Fajriyah ${ }^{2}$, Fajar Cahyadi $^{3}$ \\ 1,2,3 Program Studi Pendidikan Guru Sekolah Dasar Fakultas IImu Pendidikan \\ Universitas PGRI Semarang \\ noorkholifahsaidah@gmail.com
}

\begin{abstract}
ABSTRAK
Latar belakang penelitian ini adalah terjadinya suatu kasus di Sekolah Dasar yaitu perilaku menyimpang pada perilaku seksual pornografi terhadap siswa. Studi kasus ini dilakukan agar kejadian serupa tidak terjadi kembali di Sekolah Dasar. Tujuan penelitian ini adalah untuk mengetahui penyebab, tempat, waktu, pelaku, proses siswa dapat berperilaku menyimpang. Penelitian ini menggunakan pendekatan kualitatif dengan jenis penelitian studi kasus. Subjek penelitian ini adalah tiga orang siswa berperilaku menyimpang. Teknik pengumpulan data menggunakan metode observasi, wawancara, angket, dan dokumentasi. Uji keabsahan data menggunakan ketekunan pengamatan dan uji kredibilitas dengan melakukan triangulasi data. Teknik analisis data menggunakan teknik model interaktif Miles \& Huberman ( reduksi data, penyajian data, dan penarikan kesimpulan). Hasil penelitian menunjukkan bahwa faktor yang mempengaruhi siswa berperilaku menyimpang adalah teman sebaya karena adanya partner seks abnormal yaitu pornografi. Meski berperilaku menyimpang, siswa tersebut dalam kesehariannya menunjukkan perilaku baik seperti tertib menaati peraturan sekolah, sopan pada guru, menjalin interaksi yang baik dengan teman. Pihak sekolah, guru dan orang tua berupaya mengatasi perilaku menyimpang siswa dengan menasehati, dan memberikan perhatian khusus pada siswa agar berbuat baik.
\end{abstract}

Kata kunci: Studi Kasus,Perilaku Menyimpang.

\begin{abstract}
The background of this study is the occurrence of a case in the elementary school, namely deviant behavior on pornographic sexual behavior towards students. This case study was conducted so that similar incidents did not occur again in Elementary School. The purpose of this study is to find out the causes, places, times, actors, the process of students can behave deviant. This study uses a qualitative approach with a type of case study research. The subject of this study were three students behaving deviant. Data collection techniques use the method of observation, interviews, questionnaires, and documentation. The validity test of the data uses persistence of observation and credibility test by triangulating data. Data analysis techniques use the interactive model techniques Miles \& Huberman (data reduction, data presentation, and conclusion). The results showed that the factors that influence students' deviant behavior are peers because of the existence of abnormal sex partners, namely pornography. Although deviant behavior, these students in their daily lives show good behavior such as being obedient to obeying school rules, being polite to the teacher, establishing good interactions with friends. The school, teachers and parents try to overcome students' deviant behavior by advising, and give special attention to students to do good.
\end{abstract}

Keywords: Case Study, Deviant Behavior. 


\section{Pendahuluan}

Pendidikan merupakan salah satu bentuk interaksi seseorang yang terjadi antara pendidik dan peserta didik sekaligus tindakan sosial yang dimungkinkan berlaku melalui suatu jaringan hubungan kemanusiaan melalui peranan-peranan individu didalamnya yang diterapkan melalui proses pembelajaran. Sistem pendidikan nasional dirumuskan dalam Undang -Undang Republik Indonesia Nomor 20 tahun 2003 bahwa. Pendidikan adalah usaha sadar terencana untuk mewujudkan suasana belajar dan proses pembelajaran agar peserta didik secara aktif mengembangkan potensi dirinya untuk memiliki kekuatan spritual keagamaan, pengendalian diri, kepribadian, kecerdasan, akhlak mulia, serta ketrampilan yang diperlukan dirinya, masyarakat, bangsa dan negara.

Setiap jenjang pendidikan, dipengaruhi oleh tahap-tahap perkembangan manusia. Sarwono (2013: 29) mengatakan bahwa. Perkembangan manusia dalam empat tahap mencerminkan tahap-tahap perkembangan umat manusia sebagai berikut: 1. Masa kanakkanak (infancy): 0-4 tahun, mencerminkan tahap hewan dari evolusi umat manusia. 2. Masa anak-anak (childhood): 4-8 tahun, mencerminkan masa manusia liar, manusia yang masih menggantungkan hidupnya pada berburu. 3. Masa muda (youth atau preadolescence): 8-12 tahun, mencerminkan era manusia sudah agak mengenal kebudayaan, tetapi masih tetap setengah liar. 4. Masa remaja (adolescence): 12-25 tahun, yaitu masa topan badai, yang menceminkan kebudayaan modern yang penuh gejolak akibat pertentangan nilai-nilai.

Tahap ketiga dalam perkembangan manusia yaitu Masa muda (youth atau preadolescence) umur 8-12 tahun, termasuk dalam jenjang pendidikan sekolah dasar (SD). Karakteristik anak usia SD menurut Sumantri dan Nana Syaodih dalam Setianingsih ( 2018: 15-16) adalah senang bermain, senang bergerak, senangnya bekerja dalam kelompok, senang merasakan atau melakukan sesuatu secara langsung. Umur 8-12 tahun yang mencerminkan era manusia sudah agak mengenal kebudayaan, tetapi masih tetap setengah liar sehingga dapat menciptakan nilai positif dan nilai negatif yang dapat mempengaruhi karakter pada diri anak. Soegeng (3: 2016) mengatakan pada dasarnya pendidikan karakter adalah pendidikan nilai (value education). Dengan nilai anak dapat memilih dan memilah mana yang baik dan mana yang tidak baik, mana yang berharga mana yang tidak berharga, mana yang terpuji dan mana yang tercela, mana yang pantas dan mana yang tidak pantas, dan seterusnya.

Anak dengan pendidikan karakter lemah akan sulit membedakan mana yang baik dan mana yang tidak baik, sehingga dapat memunculkan perilaku yang bermasalah. Darwis (2006: 5-6) menjelaskan bahwa.Perilaku-perilaku yang menjadi masalah adalah perilakuperilaku individu yang berhubungan dengan orang lain atau berhubungan dengan dirinya sendiri. Masalah-masalah tersebut dapat saja kita kenal, sekalipun individu yang bersangkutan tidak mengeluh atau mempersalahkannya, tetapi orang-orang di sekelilingnya merasakan pengaruh yang mungkin cukup menganggu sebagai akibat tindakan-tindakan individu tersebut. Orang lain mungkin melihat perilaku individu tersebut bersifat destruktif, agresif, mengganggu dan menjengkelkan orang lain.

Perilaku yang menjadi masalah termasuk dalam perilaku menyimpang karena memberikan beberapa pengaruh yang mungkin cukup mengganggu. Siahaan, Jokie M.S. (2009:2) perilaku menyimpang yang dipelajari dalam sosiologi, sebagai berikut. Sosiologi mempelajari perilaku menyimpang dalam rangka mencari dasar-dasar bagi keteraturan dan ketidakteraturan sosial sehingga dapat menetapkan batasan dan peraturan apa yang akan diteliti. Pada kenyataannya, penyimpangan sosial terdapat dalam kehidupan sehari-hari. Penyimpangan ini dapat kita saksikan melalui media massa seperti surat kabar, media elektronik seperti televisi, maupun media yang lainnya. Contoh penyimpangan sosial dalam kehidupan sehari-hari adalah homoseksual, prostitusi, mengkonsumsi narkotika dan obat terlarang, pornografi, dan pornoaksi.

Berdasarkan hasil penelitian di SD Negeri Gayamsari 01 melalui observasi, siswa dilingkungan sekolah berperilaku baik, hanya saja kurang konsentrasi dalam menerima pelajaran dari guru. Dari hasil wawancara dengan siswa, siswa memang melakukan perilaku menyimpang tersebut dan merasa menyesal setelah kejadian tersebut. Siswa berisnisial "A" 
mengetahui alamat video pornografi berasal dari teman di lingkungan rumah. Siswa berinisial " $\mathrm{H}$ " dan "AL" mengetahui video pornografi melalui teman yang berinisial "A" ketika menunggu kegiatan ekstrakulikuler pramuka disekolah.

Kegiatan wawancara juga dilakukan kepada guru kelas yang tidak mengetahui secara betul kejadian kasus tersebut karena sedang tidak berada disekolah. Guru kelas hanya menerima laporan dari siswa lain mengenai kasus tersebut. Guru kelas sangat menyangkan kasus tersebut terjadi disekolah dan menimpa anak di Sekolah Dasar. Selain kepada siswa dan guru kelas, kegiatan wawancara juga dilakukan kepada kepala sekolah yang tidak mengetahui secara betul bagaimana kejadian kasus tersebut. Hasil pembagian angket orangtua menyatakan anak berperilaku baik dilingkungan keluarga dan orang tua merasa kaget dan tidak menyangka hal tersebut dapat terjadi pada anak.

\section{Metode}

Penelitian ini menggunakan pendekatan kualitatif dengan jenis penelitian stui kasus. Penelitian ini dilaksanakan di SD Negeri Gayamsari 01 Semarang khususnya di kelas 4. SD Negeri Gayamsari 01 terletak di Jalan Beruang Gayamsari, Kota Semarang. Penelitian ini dilaksanakan pada tanggal 4 sampai 11 Maret 2019.

Subjek dalam penelitian ini yaitu tiga siswa berperilaku menyimpang pada perilaku seksual pornografi. Sumber data utama dalam penelitian ini adalah kata-kata dan tindakan, sumber data tertulis, foto yang bersumber dari responden dan peneliti. Sumber data utama dalam penelitian ini adalah kata-kata dan tindakan, sumber data tertulis, foto yang bersumber dari responden dan peneliti.

Teknik pengumpulan data dalam penelitian ini adalah observasi, wawancara, dan angket. Instrumen dalam penelitian ini berupa peneliti(Human instrument), pedoman observasi, pedoman wawancara, pedoman angket (kuesioner), dan dokumentasi.

Penelitian ini menggunakan teknik analisis Miles \& Huberman, yang aktivitas dalam analisis data kualitatif selama dilapangan yaitu data reduction, data display, conclusion drawing/verification.

Uji keabsahandata dalam penelitian ini menggunakan uji ketekunan pengamatan dan dan uji kredibilitas dengan melakukan triangulasi data.

1. Penyebab perilaku menyimpang pada perilaku seksual pornografi

a. Faktor yang ada dalam diri anak

Faktor yang ada dalam diri anak yaitu lemahnya pertahanan diri adalah faktor yang ada di dalam diri untuk mengontrol dan mempertahankan diri terhadap pengaruhpengaruh negatif dari lingkungan. Jika ada pengaruh negatif berupa tontonan negatif, bujukan negatif, seperti pecandu dan pengedar narkoba, ajakan-ajakan untuk melakukan perbuatan-perbuatan negatif, sering tidak bisa menghindar dan mudah terpengaruh. Kurangnya kontrol pada diri sendiri terhadap pengaruh negatif menjadikan anak terjerumus dan melakukan hal-hal negatif.

Siswa yang melakukan perilaku menyimpang pada perilaku pornografi yang berinisial "A" memiliki kelemahan pertahanan diri. Anak sulit untuk mengontrol dan sulit mempertahankan diri terhadap pengaruh-pengaruh negatif dari lingkungan teman di rumah. Anak terpengaruh oleh teman berupa tontonan negatif dan menjadi kecanduan ketika di setiap kesempatan.

Siswa yang melakukan penyimpangan pada perilaku seksual pornografi yang berinisial "H" dan "Al" memiliki kelemahan pertahanan diri. Anak sulit mengontrol dan sulit mempertahankan diri terhadap pengaruh-pengaruh negatif dilingkungan sekolah sehingga anak menjadi korban dan ikut terpengaruh menonton tontonan negatif.

b. Penyebab kenakalan yang berasal dari lingkungan keluarga

Penyebab kenakalan yang berasal dari lingkungan keluarga yaitu anak kurang mendapatkan kasih sayang dan perhatian orang tua. Karena kurang mendapat kasih sayang dan perhatian orangtua, maka apa yang amat dibutuhkannya itu terpaksa dicari di luar rumah, seperti di dalam kelompok kawan-kawannya. 
Siswa yang melakukan peyimpangan pada perilaku pornografi berinisial "A" termasuk anak yang kurang mendapatkan kasih sayang dan perhatian orang tua. Kedua orang tua siswa bekerja sehingga perhatian dan pengawasannya kurang. Ketika dirumah anak lebih banyak bergaul dengan kakak dan teman dirumah.

c. Penyebab kenakalan yang berasal dari lingkungan masyarakat

Penyebab kenakalan yang berasal dari lingkungan masyarakat yaitu kurangnya pengawasan. Sebagian beranggapan bahwa orang tua dan guru terlalu ketat sehingga tidak memberi kebebasan baginya. Sebagian lain mengatakan bahwa orang tua mereka dan bahkan guru, tidak pernah memberikan pengawasan terhadap tingkah laku sehingga menimbulkan berbagai kenakalan.

Siswa yang melakukan peyimpangan pada perilaku pornografi berinisial "A" kurang diberikan pengawasan terhadap tingkah lakunya dirumah dan disekolah. Sehingga menimbulkan kenakalan anak yang terjadi yaitu kasus pornografi. Siswa yang berinisial "H" dan "Al" cukup dalam pengawasan terhadap tingkah lakunya dirumah namun, kurang diberikan pengawasan dalam kegiatan disekolah ketika kasus tersebut terjadi dilingkungan sekolah saat menunggu kegiatan ekstrakulikuler pramuka disekolah.

d. Adanya partner seks abnormal

Perilaku seksual adalah perilaku yang abnormal. Abnormalitas seks disebabkan karena adanya partner seks abnormal. Salah satunya adalah pornografi yang terjadi pada kasus siswa yang berinisial "A", "H" dan "Al". Perilaku tersebut termasuk dalam perilaku yang tidak normal karena adanya rekan seks yang menyimpang dari norma sosial. " $A$ " memiliki partner seks abnormal yang berasal dari teman di lingkungan tempat tinggal. " $\mathrm{H}$ " dan "Al" memiliki partner seks abnormal yang dipengaruhi oleh teman di lingkungan sekolah.

2. Tempat perilaku menyimpang pada perilaku seksual pornografi Tempat perilaku menyimpang pada perilaku seksual pornografi berdasarkan penelitian sebagai berikut:

a. Berdasarkan wawancara siswa

Berdasarkan wawancara siswa yang berinisial "A", "H" dan "Al" tempat perilaku menyimpang pada perilaku seksual pornografi terjadi di depan kelas $4 \mathrm{~B}$.

b. Berdasarkan wawancara guru

Berdasarkan wawancara dengan guru kelas 4A dan 4B tempat perilaku menyimpang pada perilaku seksual pornografi tidak mengetahui tempat kejadiannya karena tidak berada di sekolah saat kasus tersebut terjadi.

c. Berdasarkan wawancara kepala sekolah

Berdasarkan wawancara dengan Kepala sekolah tempat perilaku menyimpang pada perilaku seksual pornografi tidak mengetahui tempat kejadiannya karena tidak berada di sekolah saat kasus tersebut terjadi.

d. Berdasarkan pembagian angket orang tua

Berdasarkan pembagian angket orang tua, tempat perilaku menyimpang pada perilaku seksual pornografi hanya satu orang tua dari anak "Al" yang mengetahui tempat kejadian kasus dan orang tua dari anak " $\mathrm{A}$ " dan " $\mathrm{H}$ " tidak mengetahui tempat kejadian kasus tersebut.

3. Waktu perilaku menyimpang pada perilaku seksual pornografi

Waktu perilaku menyimpang pada perilaku seksual pornografi berdasarkan penelitian sebagai berikut:

a. Berdasarkan wawancara siswa

Berdasarkan wawancara siswa yang berinisial "A", "H" dan "Al" waktu perilaku menyimpang pada perilaku seksual pornografi terjadi ketika sedang menunggu kegiatan ekstrakulikuler pramuka.

b. Berdasarkan wawancara guru

Berdasarkan wawancara dengan guru kelas 4A dan 4B waktu perilaku menyimpang pada perilaku seksual pornografi tidak mengetahui tempat kejadiannya karena tidak berada di sekolah saat kasus tersebut terjadi. 


\section{c. Berdasarkan wawancara kepala sekolah}

Berdasarkan wawancara dengan Kepala Sekolah waktu perilaku menyimpang pada perilaku seksual pornografi tidak mengetahui tempat kejadiannya karena tidak berada di sekolah saat kasus tersebut terjadi.

d. Berdasarkan pembagian angket orang tua

Berdasarkan pembagian angket orang tua, waktu perilaku menyimpang pada perilaku seksual pornografi hanya satu orang tua dari anak "Al" yang mengetahui waktu kejadian kasus dan orang tua dari anak " $\mathrm{A}$ " dan " $\mathrm{H}$ " tidak mengetahui waktu kejadian kasus tersebut.

4. Pelaku perilaku menyimpang pada perilaku seksual pornografi

Pelaku perilaku menyimpang pada perilaku seksual pornografi berdasarkan penelitian sebagai berikut:

a. Berdasarkan wawancara siswa Berdasarkan wawancara siswa yang berinisial " $A$ ", " $H$ " dan "Al" pelaku perilaku menyimpang pada perilaku seksual pornografi adalah " $A$ ", " $H$ " dan "Al.

b. Berdasarkan wawancara guru

Berdasarkan wawancara dengan guru kelas 4B pelaku perilaku menyimpang pada perilaku seksual pornografi berjumlah tiga anak dan tidak mengetahui siapa saja yang terlibat. Sedangkan menurut guru kelas $4 \mathrm{~A}$ pelaku perilaku menyimpang pada perilaku seksual pornografi berjumlah dua anak yaitu "A" dan "Al".

c. Berdasarkan wawancara kepala sekolah

Berdasarkan wawancara dengan Kepala sekolah pelaku perilaku menyimpang pada perilaku seksual pornografi tidak mengetahui siapa saja yang terlibat dalam kasus tersebut karena tidak berada di sekolah saat kasus tersebut terjadi.

d. Berdasarkan pembagian angket orang tua

Berdasarkan pembagian angket orang tua, pelaku perilaku menyimpang pada perilaku seksual pornografi hanya satu orang tua dari anak "Al" yang mengetahui pelaku kejadian kasus, namun tidak menyebutkan siapa saja anak yang terlibat dan orang tua dari anak "A" dan " $H$ " tidak mengetahui pelaku kejadian kasus tersebut.

5. Proses perilaku menyimpang pada perilaku seksual pornografi

Proses perilaku menyimpang pada perilaku seksual pornografi berdasarkan penelitian sebagai berikut:

a. Berdasarkan wawancara siswa

Berdasarkan wawancara siswa yang berinisial "A" proses perilaku menyimpang pada perilaku seksual pornografi berawal dari ingin menonton video cino fajrin, namun justru yang diketik adalah video xxx di youtube yang diketahui siswa dari teman dirumah. "H" proses perilaku menyimpang pada perilaku seksual pornografi awalnya ingin menonton video lucu cino fajrin, namun "A" mengetik video porno dan ketika melihat ke handphone justru video porno yang terputar dan "Al" proses perilaku menyimpang pada perilaku seksual pornografi awalnya ingin menonton video lucu cino fajrin, namun Azhar mengetik video porno dan ketika melihat ke handphone justru video porno yang terputar.

b. Berdasarkan wawancara guru

Berdasarkan wawancara dengan guru kelas 4B tidak mengetahui bagaimana proses kasus tersebut terjadi. Respon beliau kasus perilaku menyimpang pada perilaku seksual pornografi yaitu merasa miris, disini faktor orangtua dan keluarga sangat berpengaruh, pergaulan anak dengan orang yang lebih dewasa juga sangat berpengaruh. Agar kejadian tersebut tidak terulang kembali disekolah yaitu ketika dikelas, guru selalu memberikan nasehat dan pengertian kepada seluruh siswa agar kejadian tersebut tidak terulang kembali disekolah. Tindak lanjut mengenai kasus tersebut yang guru lakukan adalah dengan memberikan nasehat kepada orangtua dan juga berkomunikasi dengan 
orangtua. Perubahan anak setelah kasus tersebut terjadi yaitu masih sama saja dan tidak ada perubahan.

Berdasarkan wawancara dengan guru kelas 4Avtidak mengetahui bagaimana proses kasus tersebut terjadi. Respon beliau kasus perilaku menyimpang pada perilaku seksual pornografi seharusnya tidak terjadi di sekolah, dan kejadian tersebut menimpa siswa dengan usia yang dirasa kurang wajar. Agar kejadian tersebut tidak terulang kembali disekolah yaitu berusaha menasehati, melakukan komunikasi dengan orang tua, dan berusaha menerima dan memperbaiki. Tindak lanjut mengenai kasus tersebut adalah "Al" lebih diperhatikan dan lebih diprioritaskan. Perubahan "Al" setelah kasus tersebut terjadi yaitu sikap buruknya berkurang.

c. Berdasarkan wawancara kepala sekolah

Berdasarkan wawancara dengan Kepala sekolah proses perilaku menyimpang pada perilaku seksual pornografi tidak mengetahui proses kejadiannya karena tidak berada di sekolah saat kasus tersebut terjadi. Kepala sekolah tidak memberikan respon mengenai kasus tersebut.

d. Berdasarkan pembagian angket orang tua

Berdasarkan pembagian angket orang tua, proses perilaku menyimpang pada perilaku seksual pornografi orang tua dari "Al", "A", "H" tidak mengetahui bagaimana proses kejadian kasus tersebut.

\section{Simpulan dan Saran}

Berdasarkan hasil penelitian dan pembahasan pada Bab IV dapat disimpulkan bahwa perilaku menyimpang pada perilaku seksual pornografi yang dilakukan siswa kelas IV SD Negeri Gayamsari 01 Semarang melibatkan tiga orang siswa yang dipengaruhi oleh faktorfaktor yang mempengaruhi perilaku menyimpang pada perilaku seksual pornografi yaitu faktor yang ada dalam diri anak yaitu lemahnya pertahanan diri, penyebab kenakalan yang berasal dari lingkungan keluarga yaitu anak kurang mendapatkan kasih sayang, penyebab kenakalan yang berasal dari lingkungan masyarakat yaitu kurangnya pengawasan, dan adanya partner seks abnormal.

Tempat kejadian kasus tersebut yaitu didepan kelas 4B. Waktu kejadian kasus tersebut yaitu ketika menunggu kegiatan ekstrakulikuler pramuka disekolah. Pelaku yang terlibat dalam kasus tersebut ada tiga anak yaitu Al gazali Tegar Selamet Febriyanto, Azhar Putra Cahyono, Haidar Permadi Al farisi. Proses perilaku menyimpang pada perilaku seksual pornografi berawal dari ingin menonton video cino fajrin, namun justru yang diketik adalah video xxx di youtube. Respon guru terkait kasus perilaku menyimpang pada perilaku seksual pornografi yaitu merasa miris, faktor orangtua dan keluarga sangat berpengaruh, pergaulan anak dengan orang yang lebih dewasa juga sangat berpengaruh. Agar kejadian tersebut tidak terulang kembali disekolah yaitu ketika dikelas, guru selalu memberikan nasehat dan pengertian kepada seluruh siswa agar kejadian tersebut tidak terulang kembali disekolah. Tindak lanjut mengenai kasus tersebut yang guru lakukan adalah dengan memberikan nasehat kepada orangtua dan juga berkomunikasi dengan orangtua.

Berdasarkan simpulan hasil penelitian di atas, maka disampaikan saran antara lain sebagai berikut : 1. Bagi guru: a. Guru tidak perlu ragu untuk memberi perhatian khusus terhadap siswa yang melakukan perilaku menyimpang, b. Guru dapat menjadi pengganti orang tua di lingkungan sekolah dan c.Guru dapat menjelaskan perilaku menyimpang yang dapat merugikan dirinya sendiri maupun orang lain. 2. Bagi orang tua, dengan anaknya yang melakukan perilaku menyimpang, orang tua atau wali siswa dapat memberikan perhatian yang khusus dan kasih sayang yang lebih terhadap anaknya, maka orang tua dapat memberikan arahan untuk anaknya agar tidak melakukan perilaku menyimpang lagi. Sehingga anak-anak sadar apa yang dilakukannya tidak baik dan tidak akan mengulangi perilaku-perilaku yang merugikan untuk dirinya sendiri maupun orang lain disekitarnya. 


\section{Daftar Pustaka}

Afrianingsih, Anita, Dicky Setiardi, and Mufid mufid. "Pengembangan Sikap Perilaku Anak melalui Proses Pembelajaran di Kelas Inkluisi dan Reguler." Journal of studies in early Childhood Education (J-SECE) 1.2 hlm. 91-96.

Darwis, Abu. 2006. Pengubahan Perilaku Menyimpang Murid Sekolah Dasar. Jakarta: Dapartemen Pendidikan Nasional Direktorat Jendral Pendidikan Tinggi Direktorat Ketenagaan

Desmita, 2016. Psikologi Perkembangan Peserta Didik. Bandung: PT Remaja Rosdakarya

Erlin, okvianti. (2016). "Studi Kasus Siswa Perilaku Menyimpang Siswa Kelas 1 Sd Negeri Ngemplak Nganti Sleman". Basic education. 5.19. hlm. 823-829.

Kartono, Kartini. 1989. Psikologi Abnormal dan Abnormalitas Seksual. Bandung: Mandar Maju

Kartono, Kartini. 2007. Psikologi Anak. Bandung: Mandar maju

Krisdayanti, R.N., Amin, M. and Junaidi, J., 2019. Pengaruh Good Corporate Governance Terhadap Profitabilitas Dan Kinerja Saham Perusahaan Perbankan Yang Terdaftar Di Bursa Efek Indonesia (Studi Kasus Pada Perusahaan Perbankan Yang Terdaftar Di Bursa Efek Indonesia Pada Tahun 2014-2017). Jurnal Riset Akuntansi, Volume 8, Nomor 05.

Meilani, E.R., Suwarti, S. and Wulandari, D.A., 2018. STUDI KASUS TENTANG PROSES PENGAMBILAN KEPUTUSAN MENJADI LESBI. Psycho Idea, Volume 16, Nomor 1, pp.75-87.

Moleong, J. Lexy. 2014. Metodologi Penelitian Kualitatif. Bandung: PT Remaja Rosdakarya

Puspa, J.S., Darmawan, A. and Pratiwi, N.M.I., 2018. Presepsi Mahasiwa Terhadap Tattoo Di Tubuh Manusia: Studi Kasus Mahasiswa Perempuan Fisip Untag Surabaya. Representamen, Volume 1, Nomor 02.

Sarwono, Sarlito Wirawan. 2013.Psikologi Reamaja.Jakarta: Rajawali Pers

Siahaan, Jokie M. S. 2009. Perilaku Menyimpang Pendekatan Sosiologi. Jakarta: PT Malta Printindo

Soegeng, A.Y., Ghufron Abdullah dan Kasihadi. 2016. Landasan Pendidikan Karakter. Yogyakarta: Magnum Pustaka Umum

Sudharto, dkk. 2009. Pengantar IImu Pendidikan. Semarang: FIP IKIP PGRI SEMARANG

Sugiyono. 2014. Memahami Penelitian Kualitatif. Bandung: Alfabeta

Sugiyono. 2017. Metode Penelitian Kebijakan Pendeketan Kuantitaf, Kulitatif, Kombinasi, R\&D dan Penelitian Evaluasi. Bandung: Alfabeta

Sugiyono. 2017. Metode Penelitian Pendidikan. Bandung: Alfabeta

Sulianto, Joko, Mei Fita Asri Untari, and Fitri Yulianti. (2014). "Profil Cerita Anak dan Media Boneka Tangan Dalam Metode Bercerita Berkarakter Untuk Siswa SD." Mimbar Sekolah Dasar 1.2. hlm. 113-122.

Undang-undang RI. 20 Tahun 2003 Tentang Sistem Pendidikan

Willis, Sofyan S. 2008. Remaja \& Masalahnya. Bandung: Alfabeta 
Wijaya, L.T. and Nasiwan, N., 2018. Perilaku Menyimpang Anak Buruh Migran Di Dusun Karangturi Desa Karangturi Kecamatan Kroya Kabupaten Cilacap. Social Studies, Volume 7, Nomor 1, pp.66-77.

Yudia, S.M., Cahyo, K. and Kusumawati, A., 2018. Perilaku Seksual Pranikah Pada Mahasiswa Kost (Studi Kasus Pada Perguruan Tinggi "X" Di Wilayah Jakarta Barat). Jurnal Kesehatan Masyarakat (e-Journal), Volume 6, Nomor 1, pp.819-825. 